OPEN ACCESS

Edited by:

Luca Valentini,

University of Perugia, Italy

Reviewed by:

Xiangfa Wu,

North Dakota State University,

United States

Avinash Baji,

La Trobe University, Australia

*Correspondence:

Yu Dong

Y.Dong@curtin.edu.au

Specialty section:

This article was submitted to Polymeric and Composite Materials,

a section of the journal

Frontiers in Materials

Received: 13 February 2019

Accepted: 11 April 2019

Published: 14 May 2019

Citation:

Mohammadzadehmoghadam S and

Dong Y (2019) Fabrication and Characterization of Electrospun Silk Fibroin/Gelatin Scaffolds Crosslinked With Glutaraldehyde Vapor.

Front. Mater. 6:91.

doi: 10.3389/fmats.2019.00091

\section{Fabrication and Characterization of Electrospun Silk Fibroin/Gelatin Scaffolds Crosslinked With Glutaraldehyde Vapor}

\author{
Soheila Mohammadzadehmoghadam and Yu Dong* \\ School of Civil and Mechanical Engineering, Curtin University, Perth, WA, Australia
}

Bombyx mori silk fibroin (SF) /gelatin nanofiber mats with different blend ratios of 100/0, $90 / 10$, and $70 / 30$ were prepared by electrospinning and crosslinked with glutaraldehyde (GTA) vapor at room temperature. GTA was shown to induce the conformational transition of SFs from random coils to $\beta$ sheets along with increasing nanofiber diameters with the addition of gelatin into SFs. It was found that by increasing the gelatin content, crosslinking degree was enhanced from 34\% for pure SF nanofiber mats to $43 \%$ for SF/gelatin counterparts at the blend ratio of $70 / 30$, which directly affected mechanical properties, porosity, and water uptake capacity (WUC) of prepared nanofiber mats. The addition of 10 and $30 \mathrm{wt} \%$ gelatin into SFs improved tensile strengths of SF/gelatin nanofiber mats by 10 and $27 \%$ along with moderate increases in Young's modulus by 12 and 27\%, respectively, as opposed to plain SF counterparts. However, both porosity and WUC were found to decrease from 62 to $405 \%$ for pristine SF nanofiber mats to 47 and $232 \%$ for SF/gelatin counterparts at the blend ratio of 70/30 accordingly. To further evaluate the combined effect of GTA crosslinking and gelatin content on biological response of SF/gelatin scaffolds, the proliferation assay using 3T3 mouse fibroblast was conducted. In comparison with pure SFs, cell proliferation rate was lower for SF/gelatin constructs, which declined when the gelatin content increased. These results indicated that the adverse effect of GTA crosslinking on cell response may be ascribed to imposed changes in morphology and physiochemical properties of SF/gelatin nanofiber mats. Although crosslinking could be used to improve mechanical properties of nanofiber mats, it reduced their capacity to support the cell activity. GTA optimization is required to further modulate the physico-chemical properties of SF/gelatin nanofiber mats in order to obtain stable materials with favorable bioactive properties and promote cellular responses for tissue engineering applications.

Keywords: silk fibroin (SF), gelatin, glutaraldehyde, nanofibers, electrospinning, tissue engineering 


\section{INTRODUCTION}

Tissue engineering is a cutting-edge technology for the reconstruction of damaged or lost tissues and organs with the aid of engineered tissue scaffolds in order to produce an active microenvironment to restore functions in the regeneration process, which is generally followed by the integration with host tissues. Extracellular matrix (ECM) plays a pivotal role in cell survival, migration and differentiation in addition to the presentation and storage of growth factors and signal detection (Thein-Han et al., 2009; Kim et al., 2012; Lai et al., 2014). Hence, one of main targets is to design tissue scaffolds with the recapitulation of ECM architectures by using various approaches such as phase separation (Akbarzadeh and Yousefi, 2014), selfassembly (Hartgerink et al., 2001), electrospinning (Ibrahim et al., 2017), solvent casting and particulate leaching (Sin et al., 2010). In between, electrospun nanofibers have gained enormous attention due to their intriguing characteristics including large surface area, high porosity with interconnected pores. In this process, a high electrical voltage is often applied to a polymer solution in a finite distance between a capillary and a collecting substrate. As a result, a polymer jet is ejected from the charged capillary along with the solvent evaporation to allow for the production of continuous polymeric microfibers or nanofibers received on the collecting substrate (Agarwal et al., 2008; Bhardwaj and Kundu, 2010; Ingavle and Leach, 2014).

Native ECM is a complex of polyprotein and polysaccharide with nanofibrous structures. Accordingly, it has been welldocumented that using protein and polysaccharides for biomaterials not only mimics ECM structures but also remarkably improves cell attachment, proliferation, and differentiation for tissue regeneration (Li et al., 2005; Allori et al., 2008; Khadka and Haynie, 2012; Wang et al., 2016). In this context, SFs extracted from Bombyx mori are considered as a promising fibrous biomaterial consisting of heavy chains $(350 \mathrm{kDa})$ and light chains $(25 \mathrm{kDa})$ linked together by a disulfide bond. The high molar-mass chains primarily contain Gly-Ala-Gly-Ala-Gly-Ser, which can form stable anti-parallel $\beta$-sheet crystallites and contribute greatly to the rigidity and tensile strength of SFs. The $\beta$-sheet crystalline structures of fibroins (silk-II conformation) can take up to $70 \%$ entire protein structures. Crystalline domains are surrounded by hydrophilic and non-repetitive amorphous regions (silk I conformation) with typical silk resilience (Zafar et al., 2015; Qi et al., 2017). SFs offer distinctive features including good biocompatibility, oxygen and water vapor permeability, biodegradability, low inflammatory responses, non-blood clotting effects, and good mechanical properties (Kundu et al., 2013; Li et al., 2013; Bhattacharjee et al., 2017). Hence it has attracted significant attention in the development of new advanced materials for tissue engineering applications. Furthermore, the properties of SFs may not completely meet the requirements for tissue engineering applications since it is very difficult to regulate cell proliferation and differentiation when SF nanofibers are used alone. For instance, due to the lack of bioactive peptides, SFs do not support cell biological activities as satisfactorily as other proteins like collagen and gelatin (Buitrago et al., 2018).
As a result, it appears to be more efficient to produce SFs with optimum properties when blended with other proteins (Morgan et al., 2008; Yin et al., 2009).

Gelatin is an inexpensive natural polymer derived from a partial hydrolysis of collagen, which is considered to be nonimmunogenic, biodegradable, easy to process and biocompatible for clinic use (Aldana and Abraham, 2017; Babitha et al., 2017). Such a protein also has the natural cell binding motifs like arginine-glycine-aspartic acid (RGD) that is favorable for cell activities. However, gelatin is rarely used alone owing to its high brittleness, and thus needs to be modified with several methods including crosslinking, grafting and blending (Hersel et al., 2003; Zhang et al., 2006; Wongputtaraksa et al., 2012; Taddei et al., 2013; Poursamar et al., 2016).

Notwithstanding above-mentioned properties possessed by SFs and gelatin, their applications in tissue engineering alone are quite limited arising from poor mechanical properties and unstable structures under physiological conditions (Taddei et al., 2013; Yao et al., 2016). To overcome this demerit, crosslinking methods based on natural or synthetic reagents are employed, among which glutaraldehyde (GTA) is the most common crosslinker due to its high efficiency in stabilizing collagenous materials. Despite the lower cytotoxicity of other crosslinkers, they still cannot match GTA in collagen stabilization and its risk of cytotoxicity can be reduced by the treatment prior to the usage or decreasing the GTA concentration (Cheung and Nimni, 1982; Bigi et al., 2001). Zhang et al. (2006) found that GTA vapor promoted the content of $\alpha$-helix structures for electrospun gelatin fibers, further leading to the improvements of both their thermal stability and mechanical properties. Wang et al. (2014) reported that GTA induced the conformational transition of SF films from random coils to $\beta$ sheets, and had the effect on the interaction between peptide chains of SFs, resulting in great changes in mechanical and dissolution properties.

Electrospun SF/gelatin nanofiber mats have already been developed and evaluated, as evidenced by Yin et al. (2009) to treat such mats with methanol and confirm their conformational changes from random coils to $\beta$-sheet structures. Besides, it was noted that the $\beta$-sheet structures increased with addition of gelatin, resulting in the improvement of their mechanical properties. Okhawilai et al. (2010) employed carbodiimide hydrochloride (EDC) and N-hydroxysuccinimide (NHS) solutions to crosslink electrospun Thai SF/gelatin fiber mats, which resulted in their controllable biodegradation. Shan et al. (2015) reported that wound dressings were prepared based on electrospun SF/gelatin fiber mats loaded with astragaloside IV without using any crosslinking agents despite a time-consuming electrospinning process for $30 \mathrm{~h}$. Such prepared dressings were found to enhance the cell adhesion and proliferation with good in vitro biocompatibility. The recent study carried out by Dadras Chomachayi et al. (2018) revealed that SF/gelatin fiber mats containing antibacterial agents could be crosslinked by GTA, subsequently subjected to methanol treatment. It was demonstrated that bulk hydrophilicity and mass loss of SF mats were enhanced with the addition of gelatin.

Nonetheless, to our best knowledge, crosslinking electrospun SF/gelatin nanofibers with GTA has been rarely addressed 
particularly with very limited biological applications. The aim of this study lies in the evaluation for the effect of gelatin content on material properties and structures of SF nanofibers crosslinked with GTA in order to understand the potential use of such biomaterial matrices as scaffolds for tissue engineering by means of scanning electron microscopy (SEM), Fourier transform infrared spectroscopy (FTIR), mechanical testing, degree of crosslinking tests, water uptake tests, water contact angle measurements, X-ray diffraction (XRD) analysis and biocompatibility assessment based on fibroblast cells.

\section{MATERIALS AND METHODS}

\section{Materials}

Cocoons of Bombyx mori silkworms were supplied by The Yarn Tree Co. (A quality, Greenville, SC, USA). Gelatin from porcine skin (type A, 300 bloom), glutaraldehyde (GTA) (grade I, 25\% in $\left.\mathrm{H}_{2} \mathrm{O}\right)$, hydrochloric acid $(\mathrm{HCl})$, sodium carbonate $\left(\mathrm{Na}_{2} \mathrm{CO}_{3}\right)$, lithium bromide $(\mathrm{LiBr})$, sodium bicarbonate $\left(\mathrm{NaHCO}_{3}\right)$, 2,4,6trinitro-benzene-sulfonic acid (TNBS), methanol and formic acid were purchased from Sigma Aldrich Pty Ltd (NSW, Australia). All chemicals were used without modification as materialprocessing grades.

\section{SF Preparation}

Bombyx mori cocoons were boiled in an aqueous solution of $0.02 \mathrm{M} \mathrm{Na}_{2} \mathrm{CO}_{3}$ for $30 \mathrm{~min}$, and then were rinsed thoroughly with distilled water. Degummed SFs were then dissolved in 9.3 M LiBr solutions at $60^{\circ} \mathrm{C}$ for $4 \mathrm{~h}$ and dialyzed in deionized water for $48 \mathrm{~h}$ using a dialysis membrane (12,400 MWCO, Sigma Aldrich). The dialysate was passed through a filter with the pore size of $0.22 \mu \mathrm{m}$ to remove insoluble debris and freeze-dried in order to obtain finally prepared SFs.

\section{Electrospinning}

To prepare electrospinning solutions, SFs were dissolved in 99\% formic acid and stirred for $2 \mathrm{~h}$ with a KA ${ }^{\circledR}$ - RCT basic magnetic stirrer. Afterwards, a desired amount of gelatin was added and the mixture was further stirred for $1 \mathrm{~h}$ to prepare a homogeneous solution. SF/gelatin solutions with different weight ratios (i.e., 100/0, 90/10, 70/30) were prepared at the final solution concentration of $13 \mathrm{wt} \% / \mathrm{v}$. Gelatin solution with $13 \mathrm{wt} \%$ concentration in formic acid was also prepared as a control sample. For electrospinning setup, SF/gelatin solution was loaded in a $10 \mathrm{ml}$ syringe with a blunt needle (inner diameter: $0.6 \mathrm{~mm}$ ). Solution flow rate was fixed at $0.3 \mathrm{ml} / \mathrm{h}$ and a high voltage of $16 \mathrm{kV}$ was applied to the droplets of injected solutions. Resulting nanofibers were collected on a plate collector with a distance of $13 \mathrm{~cm}$ from syringe tip. The collected nanofiber mats were dried overnight in a fume hood at room temperature. The electrospinning process was conducted on a NaBond NEU commercial nanofiber electrospinning unit (NaBond Technologies Co., Ltd., Shenzhen, China) at the ambient condition.

To enhance the structural stability of SF/gelatin fibrous scaffolds, the crosslinking process was carried out by exposing nanofibers to the vapor of $20 \%(\mathrm{v} / \mathrm{v})$ GTA at room temperature for $6 \mathrm{~h}$. After crosslinking, samples were immersed in $0.1 \mathrm{M}$ glycine aqueous solution for $30 \mathrm{~min}$ to block the residues of aldehyde groups.

\section{EXPERIMENTAL CHARACTERIZATION}

\section{Viscosity Measurement}

Prepared solution viscosities used for electrospinning were measured via a Modular Advanced Rheometer System (Haake MARS, Thermo Electron Corp., Germany) and data were extracted via HAAKE RheoWin Data Manager Software. The shear rate was linearly increased from 10 to $100 \mathrm{~s}^{-1}$ with the temperature being maintained at $25^{\circ} \mathrm{C}$.

\section{Scanning Electron Microscopy (SEM)}

Fiber morphology was observed by Zeiss EVO 40XVP SEM at an accelerating voltage of $15 \mathrm{kV}$. Samples were fixed on SEM stubs and sputter coated with platinum prior to the SEM observation. The average fiber diameter was determined by randomly measuring 100 fibers (fiber number $N=100$ ) from each SEM image using Image ${ }^{\circledR}$ software and expressed as "mean \pm standard deviation".

\section{Fourier Transform Infrared (FTIR) Spectroscopy}

The conformational characterization of fibrous scaffolds was carried out by 100FT-IR Spectrometer-Perkin (Japan) with the resolution of $4 \mathrm{~cm}^{-1}$ at the spectral range of $4,000-400 \mathrm{~cm}^{-1}$ using an attenuated total reflectance (ATR) method.

\section{X-Ray Diffraction (XRD) Analysis}

The crystalline structures of SF/gelatin nanofiber mats were determined by X-ray diffractometer D8 Advance (Bruker AXS, Germany), with a $\mathrm{Cu} \mathrm{K} \alpha$ radiation source (wavelength $\lambda=$ $0.1541 \mathrm{~nm}$ ) at $40 \mathrm{kV}$ and $40 \mathrm{~mA}$ using a LynxEye detector. All $\mathrm{XRD}$ samples were scanned from diffraction angles $2 \theta=5-30^{\circ}$ at a scan rate of $0.015^{\circ} / \mathrm{s}$.

\section{Degree of Crosslinking}

The degree of crosslinking of samples were determined using TNBS assay, as described by Bubnis and Ofner (1992). Briefly, $1-3 \mathrm{mg}$ scaffolds were immersed in $1 \mathrm{ml}$ solution with $4 \%$ $(\mathrm{w} / \mathrm{v}) \mathrm{NaHCO}_{3}$ and $1 \mathrm{ml}$ freshly prepared solution containing $0.5 \%(\mathrm{w} / \mathrm{v})$ TNBS. After $2 \mathrm{~h}$ incubation at $40^{\circ} \mathrm{C}, 3 \mathrm{~mL}$ solution with $6 \mathrm{M} \mathrm{HCl}$ was added and further heated at $60^{\circ} \mathrm{C}$ for 90 min. After cooling down to room temperature, the resulting solution was diluted with $5 \mathrm{ml}$ deionized water, and the absorbance was measured at $345 \mathrm{~nm}$ with a UV/vis spectrometer (BioPhotometer plus, Eppendorf, Hamburg, Germany). The degree of crosslinking was calculated as follows:

$$
\text { Degree of crosslinking }(\%)=\left(\frac{\mathrm{A}_{0}-\mathrm{A}_{\mathrm{C}}}{\mathrm{A}_{0}}\right) \times 100 \%
$$

Where $A_{0}$ and $A_{C}$ are the absorbances of SF/gelatin nanofiber mats before and after crosslinking, respectively. The relevant tests were performed three times under the same condition to report average data and standard deviations. 


\section{Contact Angle and Water Uptake Measurements}

To evaluate the hydrophilicity of SF/gelatin nanofiber mats, water contact angles were measured using a CAM101 goniometer (KSV Instruments Ltd, Finland). A droplet of water (volume: 5 $\mu l$ ) was deposited onto the scaffold surface and droplet images were automatically captured as a function of time. The droplet volume was controlled using a threaded plunger syringe (81341 Lauer tip syringe, Hamilton). The contact angle was calculated by CASTTM2.0 software based on these captured images. The average data were obtained from the measurements of 5 samples in each batch for test reproducibility.

In order to measure water uptake capacity (WUC) of SF and $\mathrm{SF} /$ gelatin nanofiber mats, corresponding samples in size of $1 \times$ $1 \mathrm{~cm}$ with three replicates from each mat were dried in vacuum to obtain the initial sample mass $\left(w_{0}\right)$. Subsequently, they were soaked in distilled water at room temperature for $24 \mathrm{~h}$. The excess water on the surface was removed with filter paper, which was followed by measuring the mass of wet sample $w$. The WUC was then calculated as follows:

$$
\text { Water uptake }(\%)=\left(\frac{W-W_{0}}{W_{0}}\right) \times 100 \%
$$

\section{Porosity}

The porosity of SF/gelatin nanofiber mats were determined using their apparent density $\left(\rho_{\text {apparent }}\right)$ and bulk density $\left(\rho_{\text {bulk }}\right)$ as shown in Equation (3). In between, $\rho_{\text {apparent }}$ in the unit of $\mathrm{g} / \mathrm{cm}^{3}$ was estimated on the basis of scaffold mass $m_{\text {scaffold }}(\mathrm{g})$, scaffold thickness $t(\mathrm{~cm})$, and scaffold area $A\left(\mathrm{~cm}^{2}\right)$ according to Equation (4). The samples were cut into $A=2 \mathrm{~cm}^{2}$ and the thickness of scaffolds was measured by using a micrometer at four different positions of nanofiber mats in order to obtain the average measurements.

As for the parameter of $\rho_{\text {bulk }}$, bulk densities of SFs and gelatin (i.e., $\rho_{S F}$ and $\rho_{\text {gelatin }}$ ) were referred to as 1.25 and 1.35 $\mathrm{g} / \mathrm{cm}^{3}$, respectively (Andiappan et al., 2013; Zhan et al., 2016b). Corresponding bulk density of SF/gelatin nanofiber mats $\rho_{\text {bulk }}$ was calculated in Equation (5) in which $w_{\text {gelatin }}$ and $w_{S F}$ denoted the mass fractions of gelatin and SFs, respectively. Five samples for each material batch were used with finally reported average data and standard deviations.

$$
\begin{aligned}
\text { Porosity } & =\left(1-\left[\frac{\rho_{\text {apparent }}}{\rho_{\text {bulk }}}\right]\right) \times 100 \% \\
\rho_{\text {apparent }} & =\frac{m_{\text {scaffold }}}{t \times A} \\
\frac{1}{\rho_{\text {bulk }}} & =\frac{w_{\text {gelatin }}}{\rho_{\text {gelatin }}}+\frac{w_{S F}}{\rho_{S F}}
\end{aligned}
$$

\section{Tensile Testing}

Strip-like tensile testing samples were cut from SF/gelatin nanofiber mats in dimensions of $10 \times 30 \mathrm{~mm}$ and glued onto a cardboard frame according to an explicit sample preparation procedure mentioned by Huang et al. (2004). Afterwards, the frame edges of cardboard were cut and mechanical testing was conducted on a Lloyds EZ50 universal testing machine at the crosshead speed of $10 \mathrm{~mm} / \mathrm{min}$ with ambient temperature of $25^{\circ} \mathrm{C}$ and humidity of $65 \%$ (gauge length: $30 \mathrm{~mm}$ ). Sample thickness was measured using a micrometer at five different positions on nanofiber mats to record the average data in range from 200 to $530 \mu \mathrm{m}$.

\section{Cell Culture}

Mouse fibroblast cells line 3T3 (European Collection of Cell Cultures, Porton Down, UK) were cultured in RPMI-1640 (Gibco, Thermo Fisher Scientific) supplemented with 10\% fetal bovine serum (FBS, Serana Europe GmBH), $10 \mathrm{mM}$ HEPES, $1 \mathrm{mM}$ sodium pyruvate, and $2 \mathrm{mM}$ glutamine (all from Gibco) in a humidified $37^{\circ} \mathrm{C}$ incubator, which was maintained at $5 \%$ $\mathrm{CO}_{2}$. Cells were subcultured before reaching $70 \%$ confluence (i.e., every 2 days).

\section{Proliferation Assay}

To study the cell viability on scaffolds, fibrous scaffolds were cut into disc-like samples (diameter: $12 \mathrm{~mm}$ ) and placed into petri dishes for 40-min UV sterilization. Thereafter, SF/gelatin nanofiber mats were soaked in Dulbecco modified eagle medium (DMEM, Gibco) for $1 \mathrm{~h}$ prior to cell seeding in order to facilitate the cell attachment onto nanofiber surfaces. The 3T3 cells were detached by $0.05 \%$ trypsin-EDTA (Life Technologies) from the culture flask and seeded on scaffolds in 12-well plates with a cell density of $2 \times 10^{3}$ per scaffold, and were further allowed to adhere at $37^{\circ} \mathrm{C}$ for $30 \mathrm{~min}$. After the seeding duration for $30 \mathrm{~min}$, each culture well was topped up with $2 \mathrm{ml}$ culture media. Cell growth was analyzed by transferring scaffolds into the 96well plate and adding $20 \mu \mathrm{l}$ CellTiter-Blue reagent (Promega) at different time periods, namely day 1 and day 3 for measurements. The plates were incubated in a humidified incubator at $37^{\circ} \mathrm{C}$ subjected to the equilibration with $5 \% \mathrm{CO}_{2}$ for $4 \mathrm{~h}$, and the fluorescence intensity was measured on an EnSpire Multimode plate reader (Perkin Elmer, Waltham, MA).

\section{RESULTS AND DISCUSSION}

\section{Solution Viscosity}

One of key factors in determining the fiber morphology is solution viscosity, which is directly correlated with solution concentration and molecular weight of polymers (Amariei et al., 2017). Since the concentration of SF/gelatin solution is maintained at $13 \mathrm{wt} \%$, the blend ratio of SF/gelatin can be the only parameter to affect the solution viscosity. The shear viscosity at a fixed shear rate of $100 \mathrm{~s}^{-1}$ was measured and is presented in Figure 1. It was found that solution viscosity was gradually enhanced with increasing the gelatin content, which could affect their electrospinnability and fiber morphology. A similar trend was reported by Bao et al. (2008) in which blending gelatin with SFs improved both the viscosity and spinnability of prepared solutions.

\section{Fiber Morphology}

Figures 2A-C show SEM images of GTA crosslinked SF/gelatin nanofiber mats at different blend ratios. Evidently, all scaffolds demonstrated homogeneous, bead-free nanofibrous 


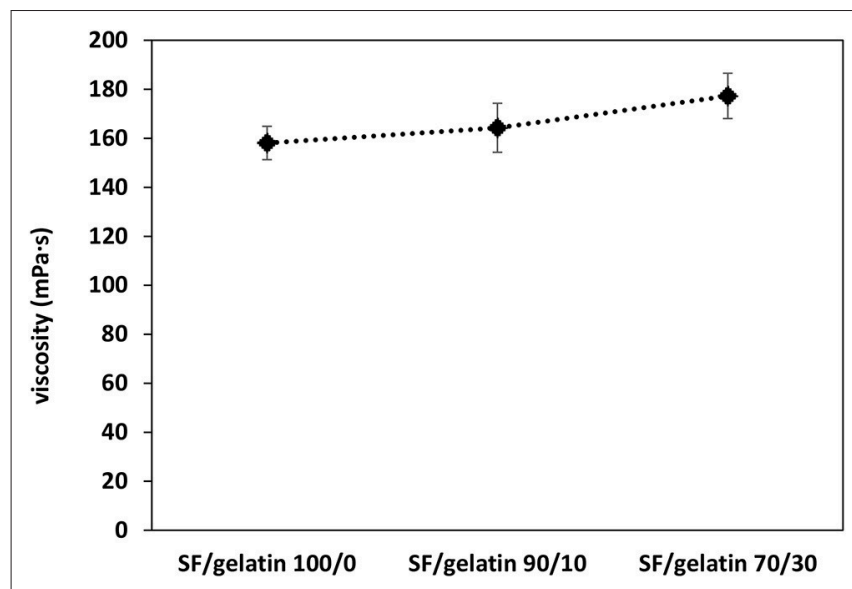

FIGURE 1 | Viscosity measurement of SF/gelatin solution at a constant shear rate of $100 \mathrm{~s}^{-1}$.

structures. Besides, nanofibers appeared to be rubbery with fusion at fiber junctions (cross-links), which was ascribed to partial dissolution of fiber segments as a result of the exposure to moisture-rich glutaraldehyde vapor. Furthermore, the slight shrinkage of nanofiber mats was manifested relative to their original sizes, which was associated with the decreasing size of inter-fibrous pores (Jeong and Park, 2014).

As seen from Figures $\mathbf{3 A - C}$, average fiber diameters for $\mathrm{SF}$ and SF/gelatin nanofiber mats at blend ratios of $90 / 10$ and $70 / 30$ were determined to be 403.5, 422.7, and $426.4 \mathrm{~nm}$, respectively. With increasing the gelatin content, it was evident that larger nanofibers with a narrow diameter distribution took place, which was in good agreement with those obtained by Dadras Chomachayi et al. (2018) for similar fiber materials. Large fiber diameters could be associated with an increase in solution viscosity with the addition of gelatin, as confirmed from our aforementioned viscosity data to induce higher jet resistance for the generation of thicker fibers. Additionally, more uniform fiber distribution implied the improvement of electrospinnability of SF/gelatin solution when the gelatin content increased (Okhawilai et al., 2010).

\section{FTIR Analysis}

The FTIR spectra of GTA modified nanofiber mats are depicted in Figure 4. The spectrum of gelatin sample shows characteristic peaks at around $3,304 \mathrm{~cm}^{-1}$ for amide $\mathrm{A}(\mathrm{N}-\mathrm{H}$ stretching vibration), $1,640 \mathrm{~cm}^{-1}$ for amide $\mathrm{I}\left(\mathrm{C}=\mathrm{O}\right.$ stretch), $1,539 \mathrm{~cm}^{-1}$ for amide II (C-N stretching and $\mathrm{N}-\mathrm{H}$ bending), and 1,240 $\mathrm{cm}^{-1}$ for amide III (N-H in phase bending and $\mathrm{C}-\mathrm{N}$ stretching vibration) (Ki et al., 2005; Gomes et al., 2013; Amadori et al., 2015; Lee et al., 2017).

With respect to plain SF nanofiber mats, FTIR peaks centered at 1,627 and $1,522 \mathrm{~cm}^{-1}$ in Figure $4 \mathbf{A}$ are assigned to amide I and amide II, respectively, which are a typical characteristic for $\beta$ sheet structures. FTIR spectra of SF/gelatin nanofiber mats at the blend ratios of $90 / 10$ and $70 / 30$ depict characteristic peaks similar

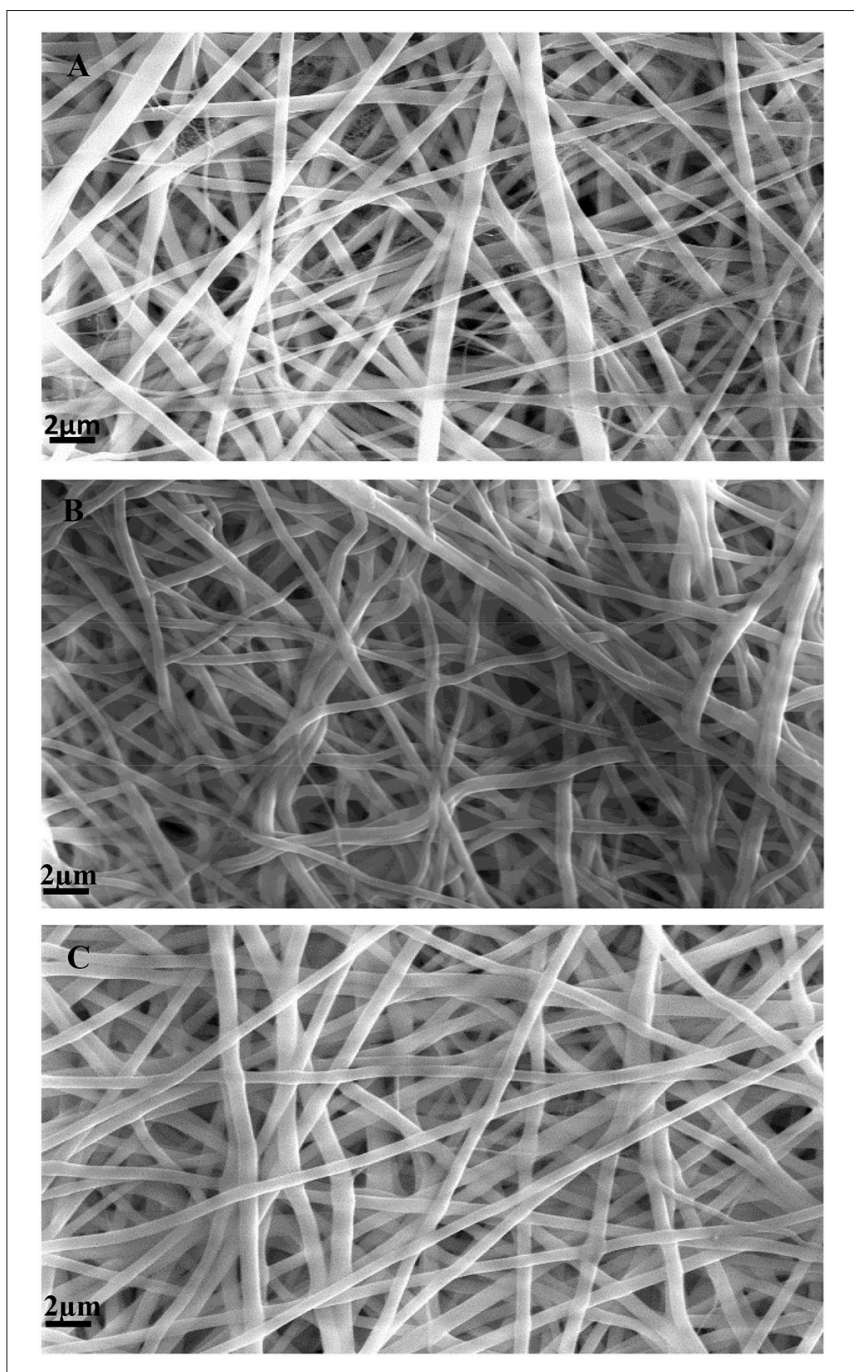

FIGURE 2 | SEM micrographs of GTA crosslinked nanofiber mats: (A) SF, (B) SF/gelatin at the blend ratio of 90/10, and (C) SF/gelatin at the blend ratio of 70/30.

to SFs, implying that the presence of gelatin does not hinder the GTA induced transformation of SF from random-coil to $\beta$-sheet conformation (Gil et al., 2006; Silva et al., 2008; Zhou et al., 2010).

\section{XRD Analysis}

Figure 5 shows the X-ray diffraction patterns of crosslinked SF, gelatin and SF/gelatin nanofiber mats. Gelatin shows a reflection at $2 \theta$ angle of $18.2^{\circ}$ corresponding to $\alpha$-helical structures (Zhan et al., 2016a). The XRD pattern of SF demonstrates diffraction peaks at 14.51 and $17.29^{\circ}$, as well as a less intense peak at $20.74^{\circ}$ to confirm the existence of $\beta$-sheet structures (Tao et al., 2007; Malay et al., 2008; De Moraes et al., 2010). In SF/gelatin nanofiber mats, diffraction patterns are almost the same as those of SF counterparts, suggesting that $\beta$-sheet conformation remains in $\mathrm{SF}$ within SF/gelatin nanofiber mats in good accordance with our obtained FTIR data. 


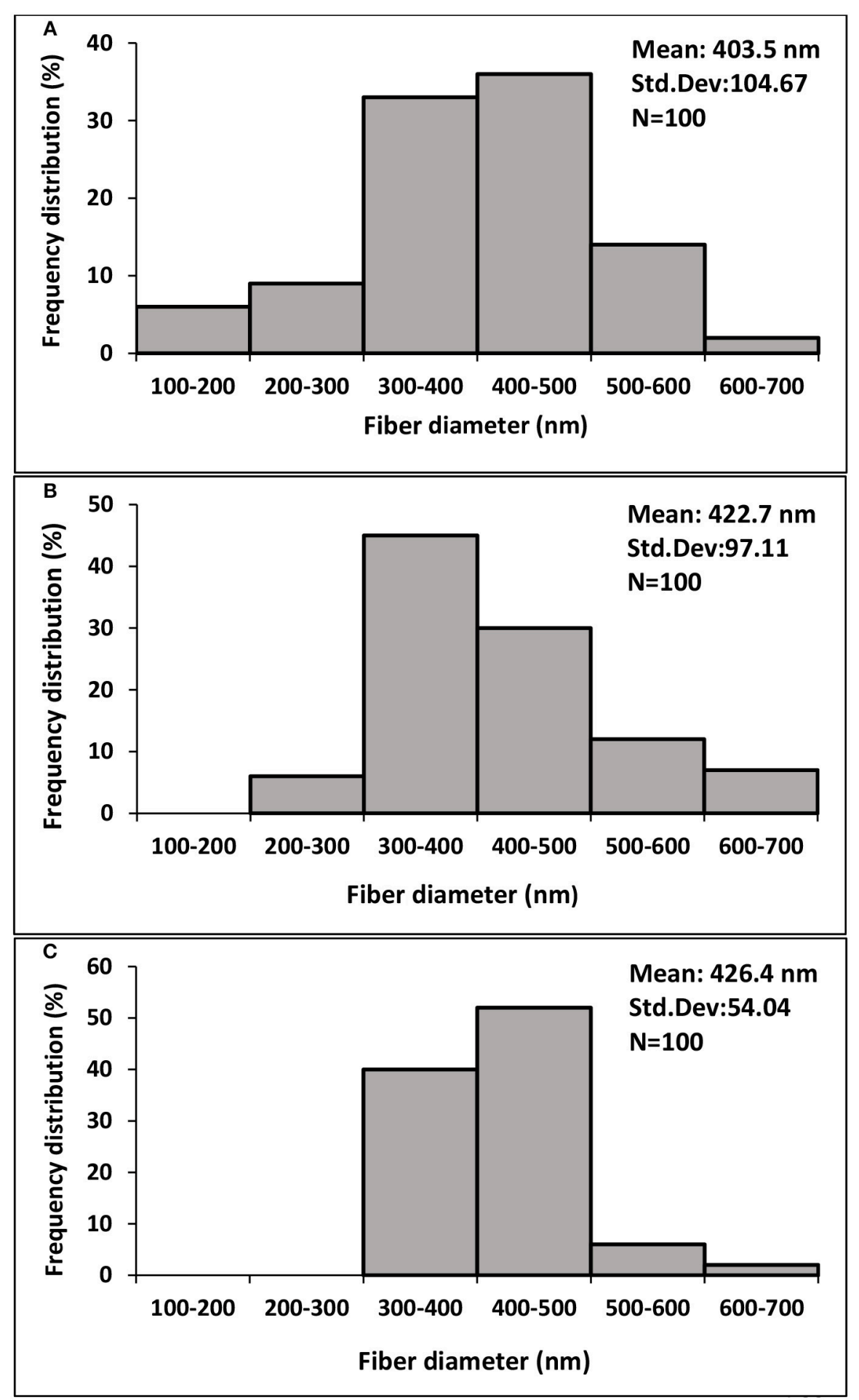

FIGURE 3 | Fiber diameter distribution diagrams of GTA crosslinked nanofiber mats based on (A) SF, (B) SF/gelatin 90/10, (C) SF/gelatin 70/30. "Std. Dev" represents the standard deviation of data.

\section{Degree of Crosslinking}

GTA crosslinked proteins through their aldehyde groups' reaction with free amino groups of lysine and hydroxylysine amino acid residues of polypeptide chains, form the bonds similar to those of Schiff bases (Cheung and Nimni, 1982; Olde Damink et al., 1995). Since gelatin had more free $-\mathrm{NH}_{2}$ groups 


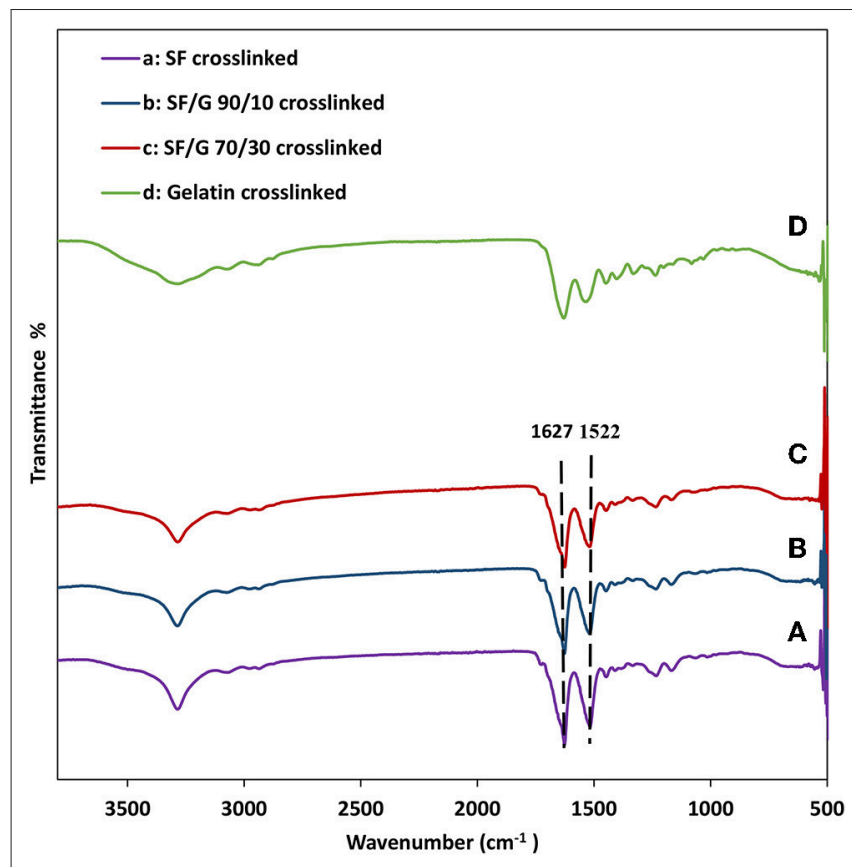

FIGURE 4 | FTIR spectra of GTA crosslinked nanofiber mats: (A) SF, (B) SF/gelatin at the blend ratio of 90/10, (C) SF/gelatin at the blend ratio of 70/30, and (D) gelatin. "SF/G" represents silk fibroin/gelatin.

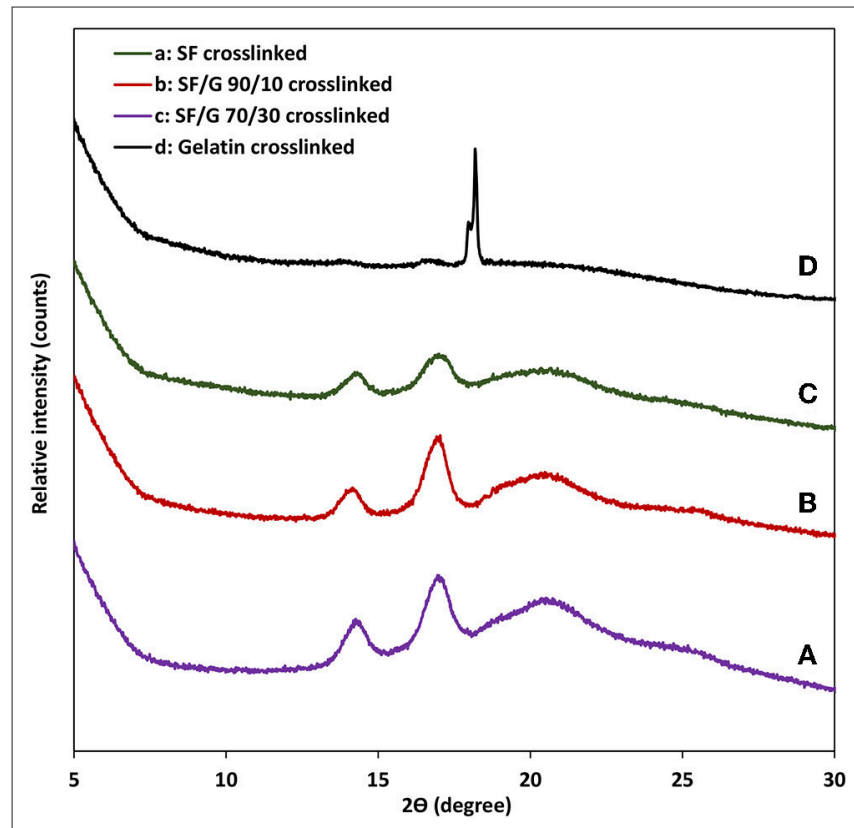

FIGURE 5 | XRD patterns of GTA crosslinked nanofiber mats: (A) SF, (B) SF/gelatin at the blend ratio of 90/10 (C) SF/gelatin at the blend ratio of 70/30, and (D) gelatin. "SF/G" represents silk fibroin/gelatin.

available for the crosslinking effect, the degree of crosslinking appeared to be relatively low for pure SFs. Whereas, the addition of gelatin enhanced the degree of crosslinking (Ratanavaraporn et al., 2014). Therefore, as shown in Figure 6A, SF/gelatin

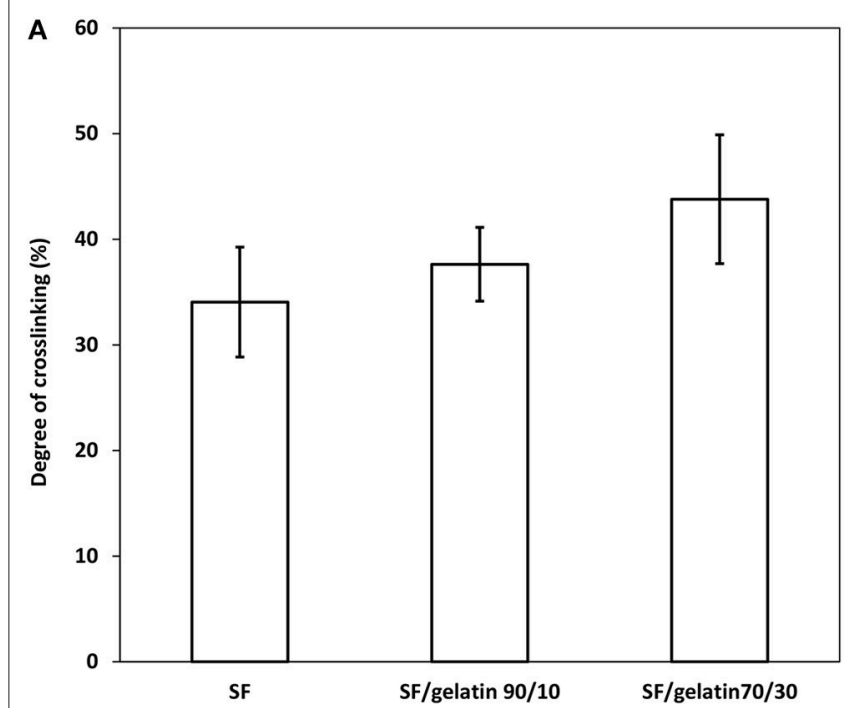

B

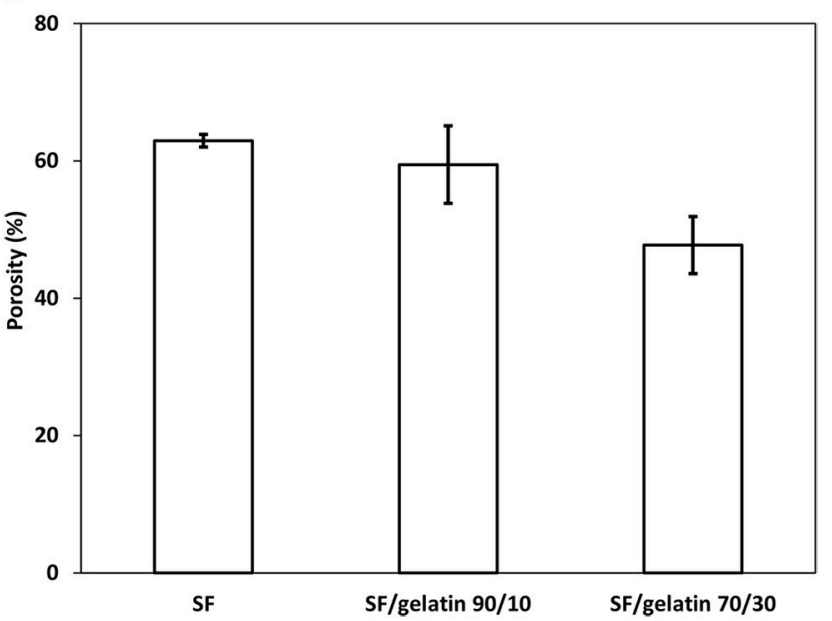

FIGURE 6 | (A) Degree of crosslinking and (B) porosity of GTA crosslinked SF nanofiber mats and SF/gelatin nanofiber mats.

nanofiber mats prepared at the blend ratio of 70/30 had the highest crosslinking degree up to $43 \%$ as opposed to the lowest value of $34 \%$ for SFs.

\section{Porosity Measurement}

It is essential to have tissue scaffolds possess a certain level of porosity in order to achieve homogeneous cell distribution and interconnection for engineered tissues. In particular, higher porosity can regulate the nutrient uptake and facilitate the oxygen diffusion (Annabi et al., 2010). As observed in Figure 6B, with respect to GTA modified nanofiber mats, increasing the gelatin content appeared to decrease the porosity of SF/gelatin nanofiber mats. The porosities of SF/gelatin nanofiber mats at the blend ratios of $90 / 10$ and 70/30 were determined to be 59 and $47 \%$, respectively as opposed to $62 \%$ for neat SF counterparts. According to our degree of crosslinking data, the addition of gelatin to SFs gave rise to a higher degree of crosslinking, which in turn yielded more fiber twining and adhesive features 


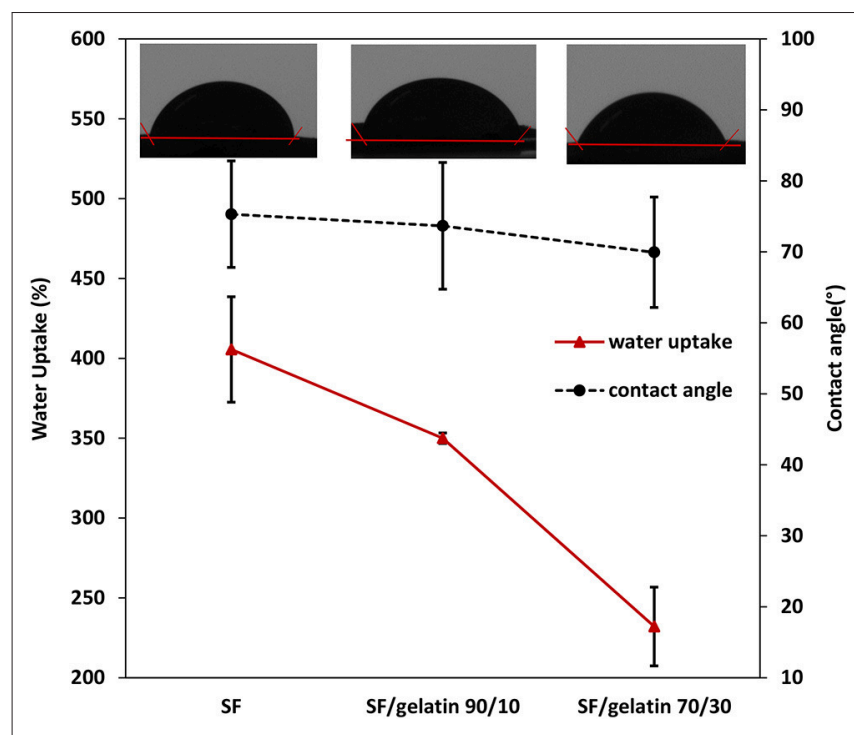

FIGURE 7 | Water uptake capacity for GTA crosslinked SF nanofiber mats and SF/gelatin nanofiber mats after $24 \mathrm{~h}$ and corresponding contact angles.

with the reduction of mat porosity. The SEM images exhibit in Figures 2A-C validated these results, indicating compressed and contracted structures for crosslinked scaffolds with higher gelatin contents.

\section{Contact Angle and Water Uptake Capacity}

To investigate the effect of gelatin on hydrophilic properties of $\mathrm{SF} /$ gelatin nanofiber mats, water contact angles and water uptake capacity of crosslinked mats were measured with associated results being presented in Figure 7. The contact angles of all nanofiber mats were $<90^{\circ}$, which was indicative of a typical hydrophilic feature. The addition of gelatin was shown to cause a slight decrease in contact angle of nanofiber mats from 75.31 $\pm 7.5^{\circ}$ for SF nanofiber mats to $69.94 \pm 7.68^{\circ}$ for SF/gelatin counterparts at the blend ratio of $70 / 30$, which was expected to be associated with the hydrophilic nature of gelatin (Kim et al., 2009). On the other hand, the WUC of SFs was much higher with the value of $405 \%$ as opposed to 350 and $232 \%$ for SF/gelatin nanofiber mats at the blend ratios of 90/10 and 70/30, respectively, as illustrated in Figure 7. Such a finding was ascribed to the incorporation of gelatin into SF matrices with GTA crosslinking effect, resulting in denser structures and increasing the compaction degree among molecules so that it was difficult for the entry of water molecules (Zhou et al., 2013). Besides, higher gelatin contents led to lower fiber porosity, thereby limiting the water diffusion into fiber mats. Xiao et al. (2012) reported a similar behavior for SF/gelatin hydrogels crosslinked with genipin, which suggested that the wettability of fiber mats could be modulated by adjusting $\mathrm{SF} /$ gelatin blend ratios.

\section{Mechanical Properties}

Figures 8A,B show tensile tested samples before and after failure along with typical stress-strain curves of nanofiber mats, respectively. It is quite evident that there are different mechanical performances between SF/gelatin nanofiber mats at various SF/gelatin blend ratios. Both tensile strength and Young's modulus increased monotonically with increasing the gelatin content in SF/gelatin nanofiber mats when compared with those of SF nanofiber mats Figures 9A,B. The incorporation of 10 and $30 \mathrm{wt} \%$ gelatin into SFs led to 10 and $27 \%$ increases in tensile strength, as well as the moderate improvements by 12 and $27 \%$ in Young's modulus, respectively when compared with those of neat SF nanofiber mats. In contrast, elongation at break decreased from 20 for SFs to $16 \%$ for $\mathrm{SF} /$ gelatin nanofiber mats at the blend ratio of $70 / 30$, which signified that increasing the gelatin content tended to cause more brittle material nature with less flexibility shown in Figure 9C. Based on crosslinking degree data in Figure 6A, the crosslinking density became higher with increasing the gelatin content, thereby molecular chains of proteins were restrained by crosslinking points, and thus led to stiffer and more robust nanofiber mats. Besides, it should be noted that the formation of intermolecular interaction between SFs and gelatin rendered the structural integrity of nanofiber mats and yielded the increase in mechanical properties (Zhu et al., 2015; Du et al., 2016; Selvaraj and Fathima, 2017). Moreover, according to morphological changes, higher gelatin content appeared to give rise to higher crosslinking density with resulting fiber fusion, thereby decreasing the porosity and increasing fiber entanglement leading to the strength enhancement (Simonet et al., 2014; Yin et al., 2017).

\section{Proliferation Assay}

The cell viability and proliferation as a function of time on scaffolds is indicative of cellular compatibility and appropriateness for tissue engineering applications. To acquire an insight into cytocompatibility of SF/gelatin nanofiber mats, 3T3 cells were seeded onto GTA modified SF/gelatin scaffolds. Their growth was quantified using the proliferation assay with associated results being displayed in Figure 10. After 1 day, no significant difference in proliferation took place between SF nanofiber mats and SF/gelatin nanofiber mats with different SF/gelatin blend ratios. However, after 3 days, cell proliferation was significantly increased in all samples. The analysis of cell proliferation profiles suggested that the rate of proliferation was higher in SFs as compared to the proliferation in SF/gelatin nanofiber mats at blend ratios of both $90 / 10$ and $70 / 30$. It was generally expected that biological responses would be improved with increasing the gelatin content, which was interpreted by the presence of more available integrin binding sites (Telemeco et al., 2005; Ghasemi-Mobarakeh et al., 2008; Wu et al., 2011). Surprisingly, an opposite trend occurred, in which higher SF/gelatin blend ratio decreased the cell proliferation. One plausible reason was that crosslinking consumed the glutamate and aspartate residues in Arg-Gly-Asp (RGD) in gelatin, and thereby reduced the cell reactivity of scaffolds (Grover et al., 2012). Moreover, the alteration in morphology, porosity and WUC of scaffolds with the addition of gelatin, as mentioned earlier, could be likely responsible for this behavior. For example, the previous study by Yeo et al. (2008) 


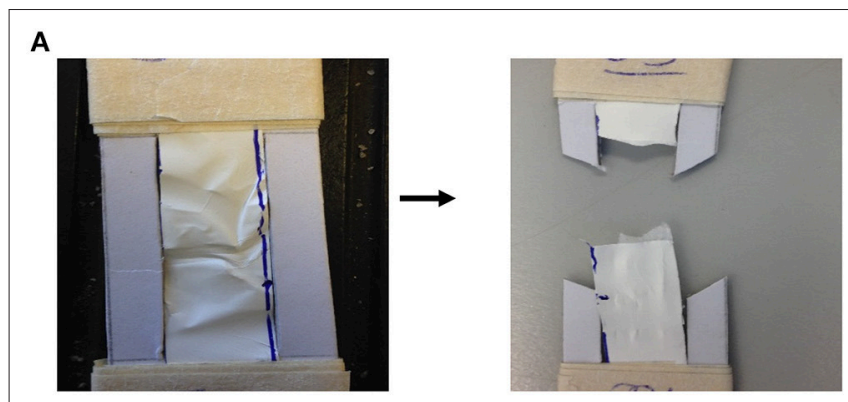

B

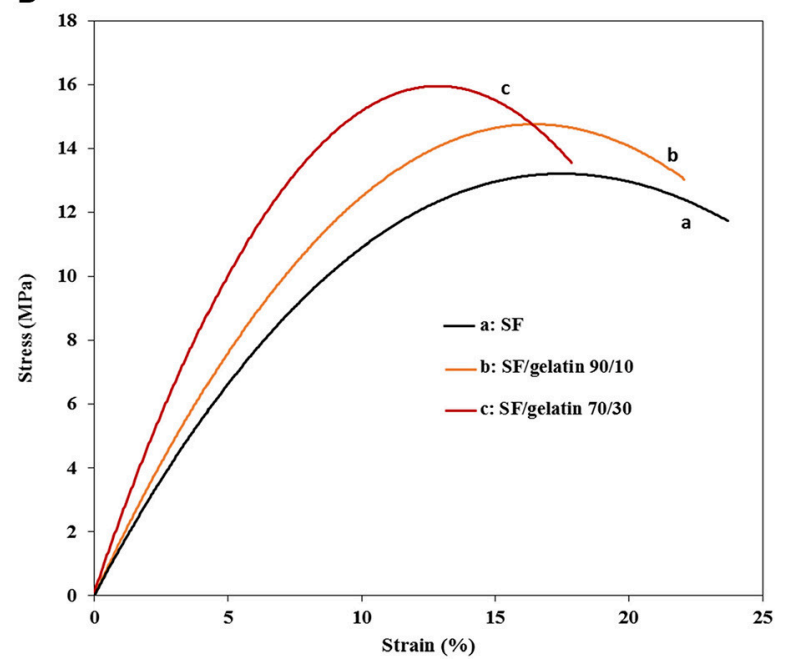

FIGURE 8 | (A) A representative testing sample before and after tensile failure, (B) Typical stress-strain curves of GTA crosslinked SF nanofiber mats and SF/gelatin nanofiber mats.

showed the reduction in cellular responses of keratinocytes for GTA crosslinked SF/collagen nanofiber mats as compared to neat SF counterparts, which was ascribed to the different conformation formation of blended SF/collagen nanofiber mats due to the interaction between collagen and SFs. Yao et al. (2016) reported that higher gelatin content in PCL/gelatin fiber mats did not necessarily result in better cell response and underlined the role of physical microenvironment such as mechanical properties in the dictation of cellular responses. In addition, Grover et al. (2012) demonstrated the detrimental effect of gelatin crosslinking on cell response as a consequence of changes in physical properties such as roughness and stiffness of gelatin films as well as a reduction in the number of available cell binding sites. However, in our system, the reduction in both porosity and WUC with increasing the gelatin content could be responsible for lower cell proliferation. It was welldocumented that highly porous structures with interconnected pores facilitated the cell migration and provided the nutrients and gas exchange for cell proliferation (Soliman et al., 2011; Stachewicz et al., 2017). Besides, higher WUC assisted the biofluid transport, cell migration, which also assisted in the growth of new cells. Moreover, the water storage helped to store growth factors and offered compressive characteristics of

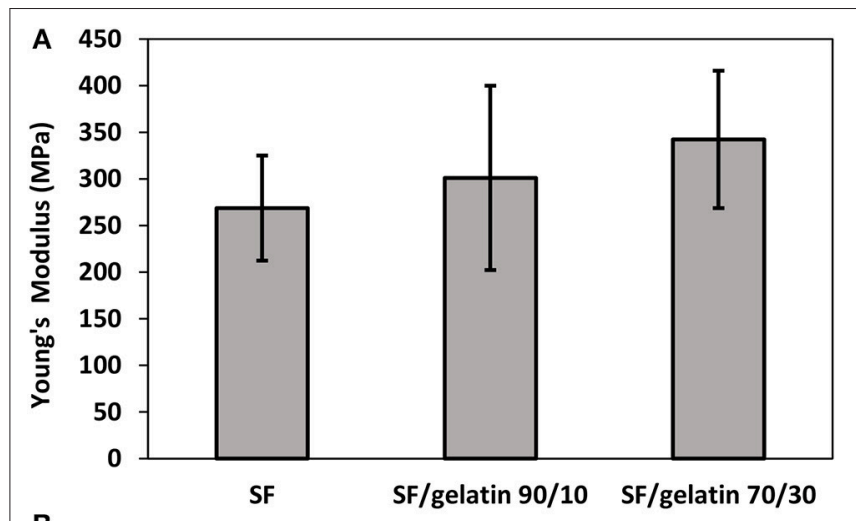

B
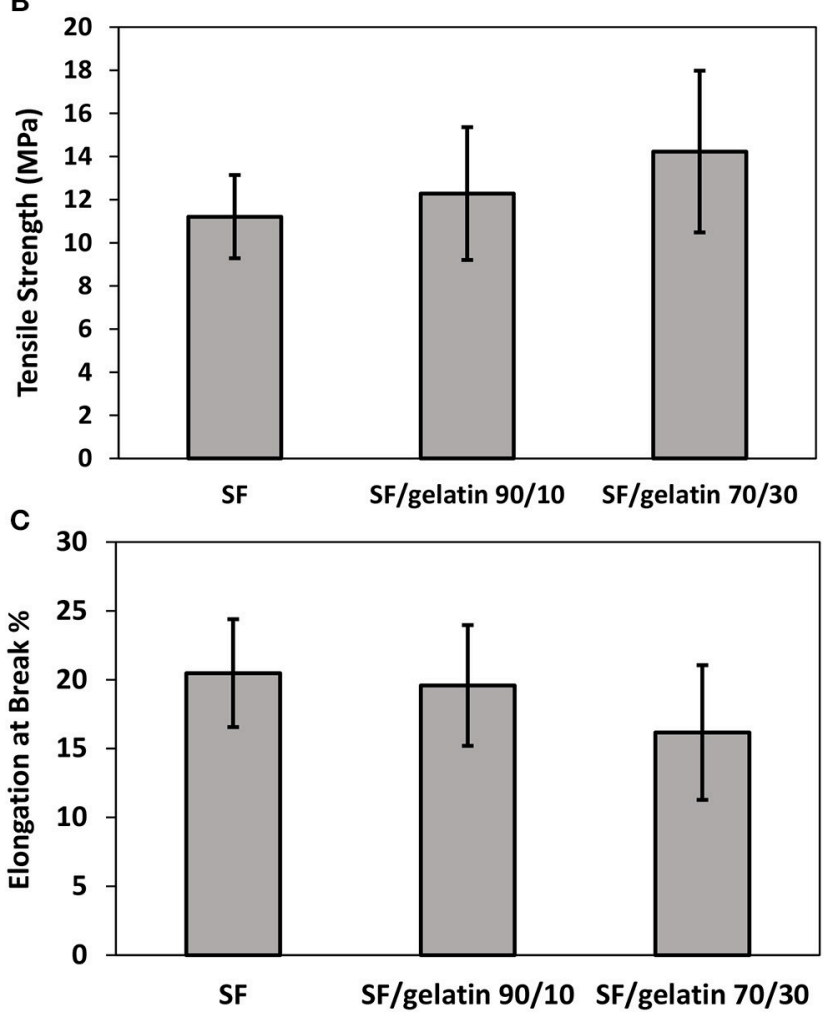

FIGURE 9 | Mechanical properties of GTA crosslinked SF nanofiber mats and SF/gelatin nanofiber mats: (A) Young's modulus, (B) tensile strength, and (C) elongation at break.

regrown tissues (Singh et al., 2016). Therefore, superior porosity and WUC of pristine SFs facilitated the nutrient transport and diffusion of signaling molecules when compared with SF/gelatin nanofiber scaffolds. Accordingly, more spaces could be provided for cell proliferation and migration, thereby yielding higher proliferation rates. Overall, it was suggested that GTA vapor could successfully stabilize SF/gelatin nanofiber mats, change their morphology and improve their mechanical properties as well. However, further studies for GTA optimization is required to modulate the physico-chemical properties of SF/gelatin nanofiber mats in order to obtain stable materials with favorable bioactive properties and promote cellular responses for tissue engineering applications. 


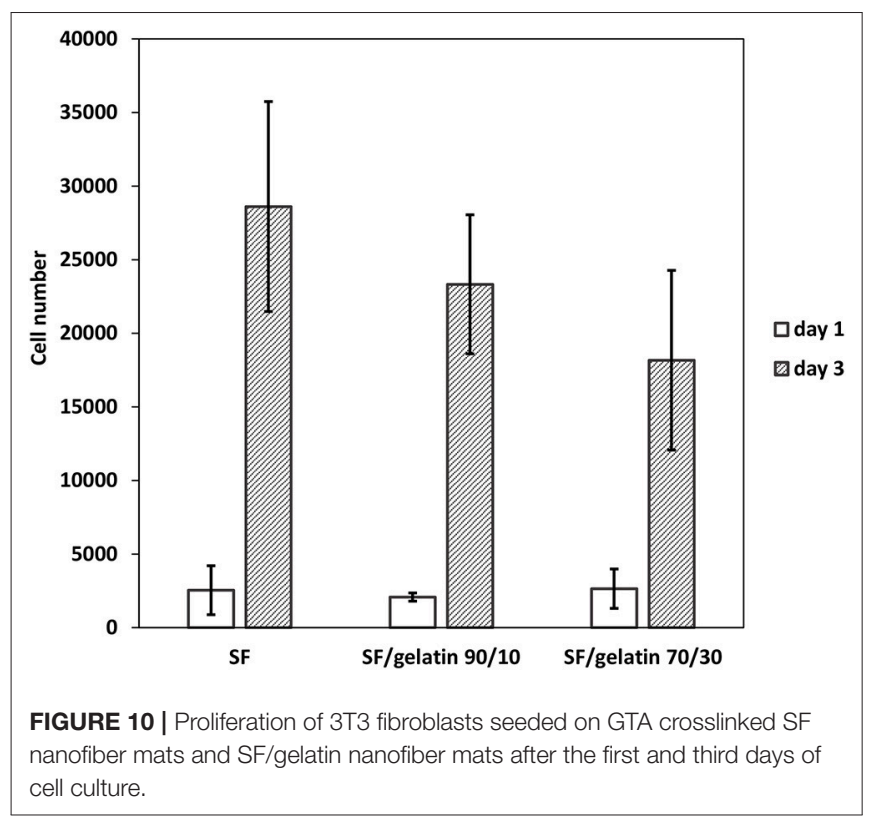

\section{CONCLUSIONS}

SF/gelatin nanofiber mats with different SF/gelatin blend ratios were successfully prepared by electrospinning and stabilized with GTA. The prepared mats possessed different porosities, WUC and tensile properties depending on the gelatin content. The incorporation of 10 and $30 \mathrm{wt} \%$ gelatin into SFs resulted in 10 and $27 \%$ increases in tensile strength and moderate improvements of Young's modulus for SF/gelatin nanofiber mats by 12 and $27 \%$, respectively, as opposed to those of SF counterparts. However, increasing the gelatin content decreased the porosity and WUC of SF/gelatin nanofiber mats accordingly. In particular, it was surprising that $\mathrm{SF} /$ gelatin

\section{REFERENCES}

Agarwal, S., Wendorff, J. H., and Greiner, A. (2008). Use of electrospinning technique for biomedical applications. Polymer 49, 5603-5621. doi: 10.1016/j.polymer.2008.09.014

Akbarzadeh, R., and Yousefi, A. M. (2014). Effects of processing parameters in thermally induced phase separation technique on porous architecture of scaffolds for bone tissue engineering. J. Biomed. Mater. Res. 102, 1304-1315. doi: $10.1002 /$ jbm.b.33101

Aldana, A. A., and Abraham, G. A. (2017). Current advances in electrospun gelatin-based scaffolds for tissue engineering applications. Int. J. Pharm. 523, 441-453. doi: 10.1016/j.ijpharm.2016.09.044

Allori, A. C., Sailon, A. M., and Warren, S. M. (2008). Biological basis of bone formation, remodeling, and repair-Part II: extracellular matrix. Tissue Eng. 14, 275-283. doi: 10.1089/ten.teb.2008.0083

Amadori, S., Torricelli, P., Rubini, K., Fini, M., Panzavolta, S., and Bigi, A. (2015). Effect of sterilization and crosslinking on gelatin films. J. Mater. Sci. 26:69. doi: 10.1007/s10856-015-5396-4

Amariei, N., Manea, L. R., Bertea, A. P., Bertea, A., and Popa, A. (2017). The influence of polymer solution on the properties of electrospun 3D nanostructures. IOP Conf. Ser.: Mater. Sci. Eng. 209:012092. doi: $10.1088 / 1757-899 \mathrm{X} / 209 / 1 / 012092$ nanofiber mats at the blend ratio of 70/30 demonstrated the lowest 3T3 fibroblast cell responses for proliferation rates. Such a finding might be partly associated with the fact that GTA crosslinking tended to induce changes in physical characteristics of microenvironments by ways of WUC and porosity at higher gelatin content levels, which clearly played an important role in the regulation of cellular functions. Overall, our initial results suggested the superiority of SF nanofiber mats to those SF/gelatin counterparts. Nonetheless, further studies are required to be conducted for the optimization of GTA crosslinking for $\mathrm{SF} /$ gelatin scaffolds, in which favorable bioactive properties of gelatin may be achieved when blended with SFs for tissue scaffolding applications.

\section{DATA AVAILABILITY}

The datasets for this article are not publicly available because SM has not finally submitted her $\mathrm{PhD}$ thesis that this article is based upon for data confidentiality. Requests to access the datasets should be directed to Y.Dong@curtin.edu.au.

\section{AUTHOR CONTRIBUTIONS}

SM did the experimental work in relation to preparation, characterization, and property measurements of material samples. SM and YD analyzed the data and jointly prepared the research manuscript.

\section{ACKNOWLEDGMENTS}

SM is grateful for 2015 Department of Mechanical Engineering Scholarship awarded by Curtin University. The authors would also like to thank Professor Deirdre Coombe from School of Pharmacy and Biomedical Sciences at Curtin University for her continuous technical supports of cell culture and proliferation assay tests.

Andiappan, M., Sundaramoorthy, S., Panda, N., Meiyazhaban, G., Winfred, S. B. Venkataraman, G., et al. (2013). Electrospun eri silk fibroin scaffold coated with hydroxyapatite for bone tissue engineering applications. Prog. Biomater. 2:6. doi: 10.1186/2194-0517-2-6

Annabi, N., Nichol, J. W., Zhong, X., Ji, C., Koshy, S., Khademhosseini, A., et al. (2010). Controlling the porosity and microarchitecture of hydrogels for tissue engineering. Tissue Eng. Part B Rev. 16, 371-383. doi: 10.1089/ten.teb. 2009.0639

Babitha, S., Rachita, L., Karthikeyan, K., Shoba, E., Janani, I., Poornima, B., et al. (2017). Electrospun protein nanofibers in healthcare: a review. Int. J. Pharm. 523, 52-90. doi: 10.1016/j.ijpharm.2017.03.013

Bao, W., Zhang, Y., Yin, G., and Wu, J. (2008). The structure and property of the electrospinning silk fibroin/gelatin blend nanofibers. e-Polymers 8:098. doi: 10.1515/epoly.2008.8.1.1131

Bhardwaj, N., and Kundu, S. C. (2010). Electrospinning: a fascinating fiber fabrication technique. Biotechnol. Adv. 28, 325-347. doi: 10.1016/j.biotechadv.2010.01.004

Bhattacharjee, P., Kundu, B., Naskar, D., Kim, H. W., Maiti, T. K., Bhattacharya, D., et al. (2017). Silk scaffolds in bone tissue engineering: an overview. Acta Biomater. 63, 1-17. doi: 10.1016/j.actbio.2017.09.027

Bigi, A., Cojazzi, G., Panzavolta, S., Rubini, K., and Roveri, N. (2001). Mechanical and thermal properties of gelatin films at different degrees of glutaraldehyde 
crosslinking. Biomaterials 22, 763-768. doi: 10.1016/S0142-9612(00) 00236-2

Bubnis, W. A., and Ofner, C. M. (1992). The determination of $\epsilon$-amino groups in soluble and poorly soluble proteinaceous materials by a spectrophotometrie method using trinitrobenzenesulfonic acid. Anal. Biochem. 207, 129-133. doi: 10.1016/0003-2697(92)90513-7

Buitrago, J. O., Patel, K. D., El-Fiqi, A., Lee, J.-H., Kundu, B., Lee, H.-H., et al. (2018). Silk fibroin/collagen protein hybrid cell-encapsulating hydrogels with tunable gelation and improved physical and biological properties. Acta Biomater. 69, 218-233. doi: 10.1016/j.actbio.2017.12.026

Cheung, D. T., and Nimni, M. E. (1982). Mechanism of crosslinking of proteins by glutaraldehyde II. Reaction with monomeric and polymeric collagen. Connect. Tissue Res. 10, 201-216. doi: 10.3109/03008208209034419

Dadras Chomachayi, M., Solouk, A., Akbari, S., Sadeghi, D., Mirahmadi, F., and Mirzadeh, H. (2018). Electrospun nanofibers comprising of silk fibroin/gelatin for drug delivery applications: thyme essential oil and doxycycline monohydrate release study. J. Biomed. Mater. Res. Part A 106, 1092-1103. doi: 10.1002/jbm.a.36303

De Moraes, M. A., Nogueira, G. M., Weska, R. F., and Beppu, M. M. (2010). Preparation and characterization of insoluble silk fibroin/chitosan blend films. Polymers 2, 719-727. doi: 10.3390/polym2040719

Du, Y., Gao, X. Q., Wang, Z. Y., Jin, D., Tong, S., and Wang, X. K. (2016). Construction and characterization of three-dimensional silk fibroin-gelatin scaffolds. J. Hard Tissue Biol. 25, 269-276. doi: 10.2485/jhtb.25.269

Ghasemi-Mobarakeh, L., Prabhakaran, M. P., Morshed, M., Nasr-Esfahani, M.H., and Ramakrishna, S. (2008). Electrospun poly( $\varepsilon$-caprolactone)/gelatin nanofibrous scaffolds for nerve tissue engineering. Biomaterials 29, 4532-4539. doi: 10.1016/j.biomaterials.2008.08.007

Gil, E. S., Frankowski, D. J., Bowman, M. K., Gozen, A. O., Hudson, S. M., and Spontak, R. J. (2006). Mixed protein blends composed of gelatin and Bombyx mori silk fibroin: effects of solvent-induded crystallization and composition. Biomacromolecules 7, 728-735. doi: 10.1021/bm050622i

Gomes, S. R., Rodrigues, G., Martins, G. G., Henriques, C. M. R., and Silva, J. C. (2013). In vitro evaluation of crosslinked electrospun fish gelatin scaffolds. Mater. Sci. Eng. C 33, 1219-1227. doi: 10.1016/j.msec.2012.12.014

Grover, C. N., Gwynne, J. H., Pugh, N., Hamaia, S., Farndale, R. W., Best, S. M., et al. (2012). Crosslinking and composition influence the surface properties, mechanical stiffness and cell reactivity of collagen-based films. Acta Biomater. 8, 3080-3090. doi: 10.1016/j.actbio.2012.05.006

Hartgerink, J. D., Beniash, E., and Stupp, S. I. (2001). Self-assembly and mineralization of peptide-amphiphile nanofibers. Science 294, 1684-1688. doi: 10.1126/science.1063187

Hersel, U., Dahmen, C., and Kessler, H. (2003). RGD modified polymers: biomaterials for stimulated cell adhesion and beyond. Biomaterials 24, 4385-4415. doi: 10.1016/S0142-9612(03)00343-0

Huang, Z.-M., Zhang, Y. Z., Ramakrishna, S., and Lim, C. T. (2004). Electrospinning and mechanical characterization of gelatin nanofibers. Polymer 45, 5361-5368. doi: 10.1016/j.polymer.2004.04.005

Ibrahim, D. M., Kakarougkas, A., and Allam, N. K. (2017). Recent advances on electrospun scaffolds as matrices for tissue-engineered heart valves. Mater.Today Chem. 5, 11-23. doi: 10.1016/j.mtchem.2017.05.001

Ingavle, G. C., and Leach, J. K. (2014). Advancements in electrospinning of polymeric nanofibrous scaffolds for tissue engineering. Tissue Eng. Part B Rev. 20, 277-293. doi: 10.1089/ten.teb.2013.0276

Jeong, L., and Park, W. H. (2014). Preparation and characterization of gelatin nanofibers containing silver nanoparticles. Int. J. Mol. Sci. 15, 6857-6879. doi: 10.3390/ijms15046857

Khadka, D. B., and Haynie, D. T. (2012). Protein-and peptide-based electrospun nanofibers in medical biomaterials. Nanomed. Nanotechnol. Biol. Med. 8, 1242-1262. doi: 10.1016/j.nano.2012.02.013

Ki, C. S., Baek, D. H., Gang, K. D., Lee, K. H., Um, I. C., and Park, Y. H. (2005). Characterization of gelatin nanofiber prepared from gelatin-formic acid solution. Polymer 46, 5094-5102. doi: 10.1016/j.polymer.2005.04.040

Kim, S. E., Heo, D. N., Lee, J. B., Kim, J. R., Park, S. H., Jeon, S. H., et al. (2009). Electrospun gelatin/polyurethane blended nanofibers for wound healing. Biomed. Mater. 4:044106. doi: 10.1088/1748-6041/4/4/ 044106
Kim, T. G., Shin, H., and Lim, D. W. (2012). Biomimetic scaffolds for tissue engineering. Adv. Funct. Mater. 22, 2446-2468. doi: 10.1002/adfm.201103083

Kundu, B., Rajkhowa, R., Kundu, S. C., and Wang, X. (2013). Silk fibroin biomaterials for tissue regenerations. Adv. Drug Deliv. Rev. 65, 457-470. doi: 10.1016/j.addr.2012.09.043

Lai, G.-J., Shalumon, K. T., Chen, S.-H., and Chen, J.-P. (2014). Composite chitosan/silk fibroin nanofibers for modulation of osteogenic differentiation and proliferation of human mesenchymal stem cells. Carbohydr. Polym. 111, 288-297. doi: 10.1016/j.carbpol.2014.04.094

Lee, J. B., Ko, Y. G., Cho, D., Park, W. H., and Kwon, O. H. (2017). Modification and optimization of electrospun gelatin sheets by electronbeam irradiation for soft tissue engineering. Biomater. Res. 21:14. doi: 10.1186/s40824-017-0100-Z

Li, M., Mondrinos, M. J., Gandhi, M. R., Ko, F. K., Weiss, A. S., and Lelkes, P. I. (2005). Electrospun protein fibers as matrices for tissue engineering. Biomaterials 26, 5999-6008. doi: 10.1016/j.biomaterials.2005.03.030

Li, Z. H., Ji, S. C., Wang, Y. Z., Shen, X. C., and Liang, H. (2013). Silk fibroin-based scaffolds for tissue engineering. Front. Mater. Sci. 7, 237-247. doi: 10.1007/s11706-013-0214-8

Malay, Ö., Yalçin, D., Batigün, A., and Bayraktar, O. (2008). SF.258 Characterization of silk fibroin/hyaluronic acid polyelectrolyte complex (PEC) films. J. Therm. Anal. Calorim. 94, 749-755. doi: 10.1007/s10973-008-9368-5

Morgan, A. W., Roskov, K. E., Lin-Gibson, S., Kaplan, D. L., Becker, M. L., and Simon, C. G. (2008). Characterization and optimization of RGD-containing silk blends to support osteoblastic differentiation. Biomaterials 29, 2556-2563. doi: 10.1016/j.biomaterials.2008.02.007

Okhawilai, M., Rangkupan, R., Kanokpanont, S., and Damrongsakkul, S. (2010). Preparation of Thai silk fibroin/gelatin electrospun fiber mats for controlled release applications. Int. J. Biol. Macromol. 46, 544-550. doi: 10.1016/j.ijbiomac.2010.02.008

Olde Damink, L. H. H., Dijkstra, P. J., Van Luyn, M. J. A., Van Wachem, P. B., Nieuwenhuis, P., and Feijen, J. (1995). Glutaraldehyde as a crosslinking agent for collagen-based biomaterials. J. Mater. Sci. Mater. Med. 6, 460-472. doi: 10.1007/BF00123371

Poursamar, S. A., Lehner, A. N., Azami, M., Ebrahimi-Barough, S., Samadikuchaksaraei, A., and Antunes, A. P. M. (2016). The effects of crosslinkers on physical, mechanical, and cytotoxic properties of gelatin sponge prepared via in-situ gas foaming method as a tissue engineering scaffold. Mater. Sci. Eng. C 63, 1-9. doi: 10.1016/j.msec.2016.02.034

Qi, Y., Wang, H., Wei, K., Yang, Y., Zheng, R.-Y., Kim, I. S., et al. (2017). A review of structure construction of silk fibroin biomaterials from single structures to multi-level structures. Int. J. Mol. Sci. 18:237. doi: 10.3390/ijms18030237

Ratanavaraporn, J., Kanokpanont, S., and Damrongsakkul, S. (2014). The development of injectable gelatin/silk fibroin microspheres for the dual delivery of curcumin and piperine. J. Mater. Sci. Mater. Med. 25, 401-410. doi: 10.1007/s10856-013-5082-3

Selvaraj, S., and Fathima, N. N. (2017). Fenugreek incorporated silk fibroin nanofibers-a potential antioxidant scaffold for enhanced wound healing. ACS Appl. Mater. Interfaces 9, 5916-5926. doi: 10.1021/acsami.6b16306

Shan, Y.-H., Peng, L.-H., Liu, X., Chen, X., Xiong, J., and Gao, J.-Q. (2015). Silk fibroin/gelatin electrospun nanofibrous dressing functionalized with astragaloside IV induces healing and anti-scar effects on burn wound. Int. J. Pharm. 479, 291-301. doi: 10.1016/j.ijpharm.2014.12.067

Silva, S. S., Maniglio, D., Motta, A., Mano, J. F., Reis, R. L., and Migliaresi, C. (2008). Genipin-modified silk-fibroin nanometric nets. Macromol. Biosci. 8, 766-774. doi: 10.1002/mabi.200700300

Simonet, M., Stingelin, N., Wismans, J. G. F., Oomens, C. W. J., Driessen-Mol, A., and Baaijens, F. P. T. (2014). Tailoring the void space and mechanical properties in electrospun scaffolds towards physiological ranges. J. Mater. Chem. B 2, 305-313. doi: 10.1039/C3TB20995D

Sin, D., Miao, X., Liu, G., Wei, F., Chadwick, G., Yan, C., et al. (2010). Polyurethane (PU) scaffolds prepared by solvent casting/particulate leaching (SCPL) combined with centrifugation. Mater. Sci. Eng. C 30, 78-85. doi: 10.1016/j.msec.2009.09.002

Singh, B. N., Panda, N. N., Mund, R., and Pramanik, K. (2016). Carboxymethyl cellulose enables silk fibroin nanofibrous scaffold with enhanced biomimetic potential for bone tissue engineering application. Carbohydr. Polym. 151, 335-347. doi: 10.1016/j.carbpol.2016.05.088 
Soliman, S., Sant, S., Nichol, J. W., Khabiry, M., Traversa, E., and Khademhosseini, A. (2011). Controlling the porosity of fibrous scaffolds by modulating the fiber diameter and packing density. J. Biomed. Mater. Res. Part A 96, 566-574. doi: $10.1002 /$ jbm.a. 33010

Stachewicz, U., Szewczyk, P. K., Kruk, A., Barber, A. H., and CzyrskaFilemonowicz, A. (2017). Pore shape and size dependence on cell growth into electrospun fiber scaffolds for tissue engineering: 2D and 3D analyses using SEM and FIB-SEM tomography. Mater. Sci. Eng. C. 95, 397-408. doi: 10.1016/j.msec.2017.08.076

Taddei, P., Chiono, V., Anghileri, A., Vozzi, G., Freddi, G., and Ciardelli, G. (2013). Silk fibroin/gelatin blend films crosslinked with enzymes for biomedical applications. Macromol. Biosci. 13, 1492-1510. doi: 10.1002/mabi. 201300156

Tao, W., Li, M., and Zhao, C. (2007). Structure and properties of regenerated Antheraea pernyi silk fibroin in aqueous solution. Int. J. Biol. Macromol. 40, 472-478. doi: 10.1016/j.ijbiomac.2006.11.006

Telemeco, T. A., Ayres, C., Bowlin, G. L., Wnek, G. E., Boland, E. D., Cohen, N., et al. (2005). Regulation of cellular infiltration into tissue engineering scaffolds composed of submicron diameter fibrils produced by electrospinning. Acta Biomater. 1, 377-385. doi: 10.1016/j.actbio.2005.04.006

Thein-Han, W. W., Saikhun, J., Pholpramoo, C., Misra, R. D., and Kitiyanant, Y. (2009). Chitosan-gelatin scaffolds for tissue engineering: physico-chemical properties and biological response of buffalo embryonic stem cells and transfectant of GFP-buffalo embryonic stem cells. Acta Biomater. 5, 3453-3466. doi: 10.1016/j.actbio.2009.05.012

Wang, Y., Wang, X., Shi, J., Zhu, R., Zhang, J., Zhang, Z., et al. (2016). A biomimetic silk fibroin/sodium alginate composite scaffold for soft tissue engineering. Sci. Rep. 6:39477. doi: 10.1038/srep39477

Wang, Y. X., Qin, Y. P., Kong, Z. J., Wang, Y. J., and Ma, L. (2014). Glutaraldehyde cross-linked silk fibroin films for controlled release. Adv. Mater. Res. 887-888, 541-546. doi: 10.4028/www.scientific.net/AMR.887-888.541

Wongputtaraksa, T., Ratanavaraporn, J., Pichyangkura, R., and Damrongsakkul, S. (2012). Surface modification of Thai silk fibroin scaffolds with gelatin and chitooligosaccharide for enhanced osteogenic differentiation of bone marrowderived mesenchymal stem cells. J. Biomed. Mater. Res. Part B Appl. Biomater. 100, 2307-2315. doi: 10.1002/jbm.b.32802

Wu, S. C., Chang, W. H., Dong, G. C., Chen, K. Y., Chen, Y. S., and Yao, C. H. (2011). Cell adhesion and proliferation enhancement by gelatin nanofiber scaffolds. J. Bioact. Compat. Polym. 26, 565-577. doi: $10.1177 / 0883911511423563$

Xiao, W., Liu, W., Sun, J., Dan, X., Wei, D., and Fan, H. (2012). Ultrasonication and genipin cross-linking to prepare novel silk fibroin-gelatin composite hydrogel. J. Bioact. Compat. Polym. 27, 327-341. doi: 10.1177/0883911512448692

Yao, R., He, J., Meng, G., Jiang, B., and Wu, F. (2016). Electrospun PCL/Gelatin composite fibrous scaffolds: mechanical properties and cellular responses. J. Biomater. Sci. Polym. Ed. 27, 824-838. doi: 10.1080/09205063.2016. 1160560
Yeo, I. S., Oh, J. E., Jeong, L., Lee, T. S., Lee, S. J., Park, W. H., et al. (2008). Collagenbased biomimetic nanofibrous scaffolds: preparation and characterization of collagen/silk fibroin bicomponent nanofibrous structures. Biomacromolecules 9, 1106-1116. doi: 10.1021/bm700875a

Yin, G., Zhang, Y., Bao, W., Wu, J., Shi, D., Dong, Z., et al. (2009). Study on the properties of the electrospun silk fibroin/gelatin blend nanofibers for scaffolds. J. Appl. Polym. Sci. 111, 1471-1477. doi: 10.1002/app. 28963

Yin, Y., Pu, D., and Xiong, J. (2017). Analysis of the comprehensive tensile relationship in electrospun silk fibroin/polycaprolactone nanofiber membranes. Membranes 7:E67. doi: 10.3390/membranes7040067

Zafar, M. S., Belton, D. J., Hanby, B., Kaplan, D. L., and Perry, C. C. (2015). Functional material features of Bombyx mori silk light versus heavy chain proteins. Biomacromolecules 16, 606-614. doi: 10.1021/bm501667j

Zhan, J., Morsi, Y., Ei-Hamshary, H., Al-Deyab, S. S., and Mo, X. (2016a). In vitro evaluation of electrospun gelatin-glutaraldehyde nanofibers. Front. Mater. Sci. 10, 90-100. doi: 10.1007/s11706-016-0329-9

Zhan, J., Morsi, Y., Ei-Hamshary, H., Al-Deyab, S. S., and Mo, X. (2016b). Preparation and characterization of electrospun in-situ cross-linked gelatingraphite oxide nanofibers. J. Biomater. Sci. Polym. Ed. 27, 385-402. doi: $10.1080 / 09205063.2015 .1133156$

Zhang, Y. Z., Venugopal, J., Huang, Z. M., Lim, C. T., and Ramakrishna, S. (2006). Crosslinking of the electrospun gelatin nanofibers. Polymer 47, 2911-2917. doi: 10.1016/j.polymer.2006.02.046

Zhou, J., Cao, C., Ma, X., and Lin, J. (2010). Electrospinning of silk fibroin and collagen for vascular tissue engineering. Int. J. Biol. Macromol. 47, 514-519. doi: 10.1016/j.ijbiomac.2010.07.010

Zhou, Z., Yang, Z., Huang, T., Liu, L., Liu, Q., Zhao, Y., et al. (2013). Effect of chemical cross-linking on properties of gelatin/hyaluronic acid composite hydrogels. Polym. Plastics Technol. Eng. 52, 45-50. doi: 10.1080/03602559.2012.718400

Zhu, J., Yang, F., He, F., Tian, X., Tang, S., and Chen, X. (2015). A tubular gelatin scaffold capable of the time-dependent controlled release of epidermal growth factor and mitomycin C. Colloids Surf. B Biointerf. 135, 416-424. doi: 10.1016/j.colsurfb.2015.06.049

Conflict of Interest Statement: The authors declare that the research was conducted in the absence of any commercial or financial relationships that could be construed as a potential conflict of interest.

Copyright $\odot 2019$ Mohammadzadehmoghadam and Dong. This is an open-access article distributed under the terms of the Creative Commons Attribution License (CC $B Y)$. The use, distribution or reproduction in other forums is permitted, provided the original author(s) and the copyright owner(s) are credited and that the original publication in this journal is cited, in accordance with accepted academic practice. No use, distribution or reproduction is permitted which does not comply with these terms. 